\title{
A Prospective Study on Local Complications of Primary Total Laryngectomy/Laryngopharyngectomy for Laryngeal and Hypopharyngeal Malignancies
}

\author{
Shashidhar Kallappa ${ }^{1,}$, , Navaneetha Kallidil Kallavalappil ${ }^{2}$ \\ ${ }^{1}$ Department of Surgical Oncology, Karnataka Institute of Medical Sciences, Hubli, India \\ ${ }^{2}$ Department of Otorhinolaryngology, Karnataka Institute of Medical Sciences, Hubli, India \\ Email address: \\ drshashi75@rediffmail.com (S. Kallappa), navaneethakallidil@gmail.com (N. K. Kallavalappil) \\ ${ }^{*}$ Corresponding author
}

\section{To cite this article:}

Shashidhar Kallappa, Navaneetha Kallidil Kallavalappil. A Prospective Study on Local Complications of Primary Total Laryngectomy/Laryngopharyngectomy for Laryngeal and Hypopharyngeal Malignancies. International Journal of Clinical Oncology and Cancer Research. Vol. 6, No. 2, 2021, pp. 49-55. doi: 10.11648/j.ijcocr.20210602.11

Received: March 12, 2021; Accepted: March 27, 2021; Published: April 7, 2021

\begin{abstract}
Background: Carcinoma larynx is one among the most common head and neck malignancy which accounts for $2 \%$ of all cancers whereas hypopharyngeal cancer is one of the most aggressive tumor with poorer prognosis. Total laryngectomy/laryngopharyngectomy (TL/TLP) is the treatment of choice for locally advanced laryngeal and hypopharyngeal cancers. Objectives: To study the complications associated with primary TL/TLP along with the sociodemographic profile and clinicopathologic features of laryngeal and hypopharyngeal cancers. We also aimed to assess the risk factors associated with complications. Methods: All stage III or IVA laryngeal and hypopharyngeal malignancy cases as per American Joint Committee on Cancer (AJCC) $8^{\text {th }}$ edition staging, who underwent primary total laryngectomy/total laryngopharyngectomy during the year 2018-2019 in our institute, KIMS Hubli, have been studied. Sociodemographic profile and clinicopathological features were noted. These patients were followed up for 6 months for any local complications. Results: Mean age of the study population was 58 years with male predominance. Primary glottic carcinoma was most common. Most common presenting symptom was change in voice and most common anatomical site involved was true cords. Overall complication rate was $32 \%$. Most common complication encountered was wound infection and pharyngocutaneous fistula $(8 \%$ each). As complications set in length of hospital stay increases. We found significant association with PCF and length of hospital stay. Conclusion: With proper case selection, and regular wound care, complications can be avoided in case of TL/TLP. Once complications set in, it increases hospital stay and the expenditure, hence is traumatizing to the patient and hence should be avoided.
\end{abstract}

Keywords: Laryngectomy, Carcinoma, Larynx, Hypopharynx, Complications

\section{Introduction}

Laryngeal cancer is one among the common head and neck malignancies. It accounts for almost $2 \%$ of all cancers [1]. Hypopharyngeal cancers are also common in our country and are more aggressive and have poorer prognosis as compared to laryngeal cancers, as they present in late stages. The incidence of both malignancies are increasing over time in most part of the world [2]. There is a male predominance in both laryngeal and hypopharyngeal cancers.

Laryngeal cancer is subdivided into supraglottic, glottic and subglottic, based on subsites with primary subglottic being rare. Hypopharyngeal cancers can be divided based on its subsites as pyriform fossa malignancy, post cricoid malignancy and posterior pharyngeal wall malignancy. Among this pyriform fossa malignancy is the most common one. Most of the laryngeal and hypopharyngeal cancers are squamous cell carcinoma followed by adenocarcinoma. Biopsy is needed for a definitive diagnosis.

After clinical evaluation followed by radiological evaluation it is staged according to AJCC TNM classification. The various treatment modalities available include surgery, radiotherapy and chemotherapy. Total laryngectomy and total laryngopharyngectomy are the treatment of choice for locally 
advanced laryngeal and hypopharyngeal cancers respectively. After the advent of chemoradiation there is a shift in the treatment from primary surgery to organ preservation strategies [3]. Total laryngectomy/laryngopharyngectomy (TL/TLP) is associated with early as well as late complications. Many studies has been done to assess risk factors associated with the complications of total laryngectomy/laryngopharyngectomy. In this study we look into the complications associated with total laryngectomy/laryngopharyngectomy in our hospital setting, along with the clinicopathological evaluation of laryngeal and hypopharyngeal malignancies.

\section{Methodology}

Twenty five patients who underwent total laryngectomy /total laryngopharyngectomy as primary treatment for stage III/IVA laryngeal and hypopharyngeal malignancy during the study period 2018-2019 in our institution has been studied for their sociodemographic profile and clinicopathological features, the type of reconstruction and neck dissection undergone, the voice rehabilitation methods adopted and the complications encountered till 6 months after the surgery. The risk factors associated with complications were assessed to derive any statistical significance. The surgery was done under sterile precautions after optimizing comorbidities if any. Prior to surgery, informed written consent was obtained from the patient. After a thorough pre-operative evaluation and pre-anesthetic check-up, the patients were posted for surgery. Preoperative parts preparation is done. General anesthesia was induced via oral endotracheal intubation. If patient was tracheostomised prior, flexometallic tube was inserted via the existing stoma. Ryle's tube is inserted on table. After painting and draping, Gluck-Sorensons incision is taken and subplatysmal flaps elevated. Neck dissection is performed according to the stage and nodal status of the patient. After mobilizing the larynx, superior and inferior vascular pedicle is ligated on the involved side. Hemithyroidectomy/total thyroidectomy is done along with the TL depending on the extend of the tumor. Transvallecular entry is done and entered larynx, and whole of the larynx with an inferior margin of 1 $\mathrm{cm}$ is removed, after creating a stoma in the trachea and changing the ventilating tube. In case pyriform fossa is involved circumferential partial pharyngectomy is done. Stomal ends are sutured to the skin and a permanent tracheostome created. If remnant pharyngeal mucosa is more than $3 \mathrm{~cm}$ primary closure of neopharynx was done. Otherwise pectoralis major myocutaneous flap reinforcement was done. Neopharynx closed in layers. Drains are secured and the wound closed in layers. Tight dressing given. Post operatively for suctioning tracheostomy tube was kept for 2 days. Feeding started postoperatively on first or second day through nasogastric tube (NG tube). Drain removed postoperatively when drain amount was less than $50 \mathrm{ml}$. Staplers removed after 1 week and NG tube removed on $10^{\text {th }}$ day after trial feeds. Patients are discharged usually 2 weeks after surgery and reviewed after 2 weeks and then monthly for 6 months.

\section{Statistical Analysis}

Statistical analysis was done using SPSS 20.0 software and $\mathrm{p}$ was considered statistically significant when less than 0.05 .

\section{Results}

Forty percent of study population was in the age group 51-60 and another $40 \%$ in the age group 61-70. The mean age (years) of our population was 58.24 \pm 8.87 (range: 33-70). Twenty four $(96.0 \%)$ out of the twenty five patients were males. Male: female ratio was 24:1. Nineteen cases were laryngeal malignancy whereas rest were hypopharyngeal malignancy. Among laryngeal malignancies glottic malignancy was the most common. The most common presenting symptom was change in voice $(80 \%)$ followed by stridor (40\%) and dysphagia (28\%). 64\% of population were smokers, $40 \%$ used smokeless tobacco, and $52 \%$ alcoholics. Most common site involved by the tumor was true cords $(68 \%)$ followed by pyriform fossa and arytenoids (36\% each). Emergency tracheostomy rate was $40 \%$.

Table 1. Shows sociodemographic profile and clinicopathologic features of the study population.

\begin{tabular}{|c|c|c|c|c|}
\hline Sociodemographic details and clinicopathologic features & $\operatorname{Mean} \pm$ SD & Median (IQR) & Min-Max & Frequency (\%) \\
\hline Age (Years) & $58.24 \pm 8.87$ & $60.00(54.00-65.00)$ & $33.00-$ & 70.00 \\
\hline \multicolumn{5}{|l|}{ Age } \\
\hline $31-40$ Years & $1(4.0 \%)$ & & & \\
\hline 41-50 Years & $4(16.0 \%)$ & & & \\
\hline 51-60 Years & $10(40.0 \%)$ & & & \\
\hline $61-70$ Years & $10(40.0 \%)$ & & & \\
\hline 71-80 Years & $0(0.0 \%)$ & & & \\
\hline \multicolumn{5}{|l|}{ Gender } \\
\hline Male & $24(96.0 \%)$ & & & \\
\hline Female & $1(4.0 \%)$ & & & \\
\hline \multicolumn{5}{|l|}{ Socio-Economic Status } \\
\hline Lower Middle & $2(8.0 \%)$ & & & \\
\hline Upper Lower & $14(56.0 \%)$ & & & \\
\hline Lower & $9(36.0 \%)$ & & & \\
\hline Ulceroproliferative & $12(48.0 \%)$ & & & \\
\hline
\end{tabular}




\begin{tabular}{|c|c|c|c|c|}
\hline Sociodemographic details and clinicopathologic features & Mean \pm SD & Median (IQR) & Min-Max & Frequency (\%) \\
\hline Proliferative & $12(48.0 \%)$ & & & \\
\hline Endophytic & $1(4.0 \%)$ & & & \\
\hline \multicolumn{5}{|l|}{ FNAC of palpable lymph node } \\
\hline Squamous Cell Carcinoma & $2(100.0 \%)$ & & & \\
\hline \multicolumn{5}{|l|}{ Biopsy HPR } \\
\hline SCC-Well Differentiated & $16(64.0 \%)$ & & & \\
\hline SCC-Moderately Differentiated & $8(32.0 \%)$ & & & \\
\hline SCC-Poorly Differentiated & $1(4.0 \%)$ & & & \\
\hline Emergency tracheostomy done & $10(40.0 \%)$ & & & \\
\hline \multicolumn{5}{|l|}{ Diagnosis based on subsite } \\
\hline CA Supraglottis & $3(12.0 \%)$ & & & \\
\hline CA Glottis & $16(64.0 \%)$ & & & \\
\hline CA Hypopharynx (PF) & $6(24.0 \%)$ & & & \\
\hline CA Hypopharynx (PCA) & $0(0.0 \%)$ & & & \\
\hline \multicolumn{5}{|l|}{ Diagnosis } \\
\hline Laryngeal Carcinoma & $19(76.0 \%)$ & & & \\
\hline Hypopharyngeal Carcinoma & $6(24.0 \%)$ & & & \\
\hline \multicolumn{5}{|l|}{ T Stage } \\
\hline $\mathrm{T} 2$ & $1(4.0 \%)$ & & & \\
\hline $\mathrm{T} 3$ & $11(44.0 \%)$ & & & \\
\hline $\mathrm{T} 4 \mathrm{a}$ & $13(52.0 \%)$ & & & \\
\hline $\mathrm{T} 4 \mathrm{~b}$ & $0(0.0 \%)$ & & & \\
\hline \multicolumn{5}{|l|}{ N Stage } \\
\hline N0 & $23(92.0 \%)$ & & & \\
\hline N1 & $2(8.0 \%)$ & & & \\
\hline \multicolumn{5}{|l|}{ Tumor Stage } \\
\hline III & $12(48.0 \%)$ & & & \\
\hline IVA & $13(52.0 \%)$ & & & \\
\hline \multicolumn{5}{|l|}{ Neck Dissection } \\
\hline SND & $23(92.0 \%)$ & & & \\
\hline MRND & $2(8.0 \%)$ & & & \\
\hline \multicolumn{5}{|l|}{ Reconstruction } \\
\hline Primary Closure & $23(92.0 \%)$ & & & \\
\hline PMMC & $2(8.0 \%)$ & & & \\
\hline \multicolumn{5}{|l|}{ Voice Rehabilitation } \\
\hline Esophageal Speech & $16(64.0 \%)$ & & & \\
\hline Primary TEP & $9(36.0 \%)$ & & & \\
\hline Hospital Stay (Days) & $26.68 \pm 6.58$ & $25.00(22.00-28.00)$ & $20.00-$ & 50.00 \\
\hline \multicolumn{5}{|l|}{ Tumor HPR } \\
\hline SCC-Well Differentiated & $17(68.0 \%)$ & & & \\
\hline SCC-Moderately Differentiated & $7(28.0 \%)$ & & & \\
\hline SCC-Poorly Differentiated & $1(4.0 \%)$ & & & \\
\hline \multicolumn{5}{|l|}{ pT Stage } \\
\hline pT2 & $2(8.0 \%)$ & & & \\
\hline pT3 & $10(40.0 \%)$ & & & \\
\hline pT4a & $13(52.0 \%)$ & & & \\
\hline \multicolumn{5}{|l|}{ pN Stage } \\
\hline No & $18(72.0 \%)$ & & & \\
\hline N1 & $4(16.0 \%)$ & & & \\
\hline N3b & $3(12.0 \%)$ & & & \\
\hline \multicolumn{5}{|l|}{ Postoperative CT/RT } \\
\hline Given & $14(56.0 \%)$ & & & \\
\hline Not Given & $11(44.0 \%)$ & & & \\
\hline
\end{tabular}

Primary closure was done for $92 \%$ cases, rest $8 \%$ underwent reconstruction with Pectoralis major myocutaneous flap (PMMC flap). Nine patients (36\%) underwent primary TEP for voice rehabilitation whereas $64 \%$ were taught esophageal speech.

Most common histological variant was well differentiated squamous cell carcinoma (68\%) followed by moderately differentiated (28\%) and poorly differentiated (4\%) squamous cell carcinoma. This is as per Broder's classification.

Pathological T stage T4 $(52 \%)$ were more common than T3 $(40 \%)$ and $\mathrm{T} 2(8 \%)$. On pathological staging 3 were N3b
(12\%), 4 were N1 (16\%) and rest N0. Postoperative adjuvant therapy was given to 14 cases $(56 \%)$.

Table 2. Shows incidence of various complications.

\begin{tabular}{ll}
\hline COMPLICATIONS & PERCENTAGE \\
\hline Wound infection & $8 \%$ \\
Wound seroma & $4 \%$ \\
Chyle leak & $4 \%$ \\
PC Fistula & $8 \%$ \\
Flap necrosis & $4 \%$ \\
Stomal stenosis & $8 \%$ \\
Stomal recurrence & $4 \%$ \\
\hline
\end{tabular}


Overall complication rate was $32 \%$. There was no on table complication encountered. Most common complication encountered was wound infection and pharyngocutaneous fistula/PCF ( $8 \%$ each). One case of wound infection has gone for flap necrosis. There were also two cases $(8 \%)$ of stomal stenosis, one with stomal recurrence. One case of chyle leak and one case of wound seroma was noted. None of the risk factors were proven to be statistically associated with postoperative complications. Mean length of hospital stay among TL/TLP cases with wound complications was 31.88 where as it was 24.24 days in case of cases without complications. Increase in hospital stay was statistically associated with occurrence of PCF.

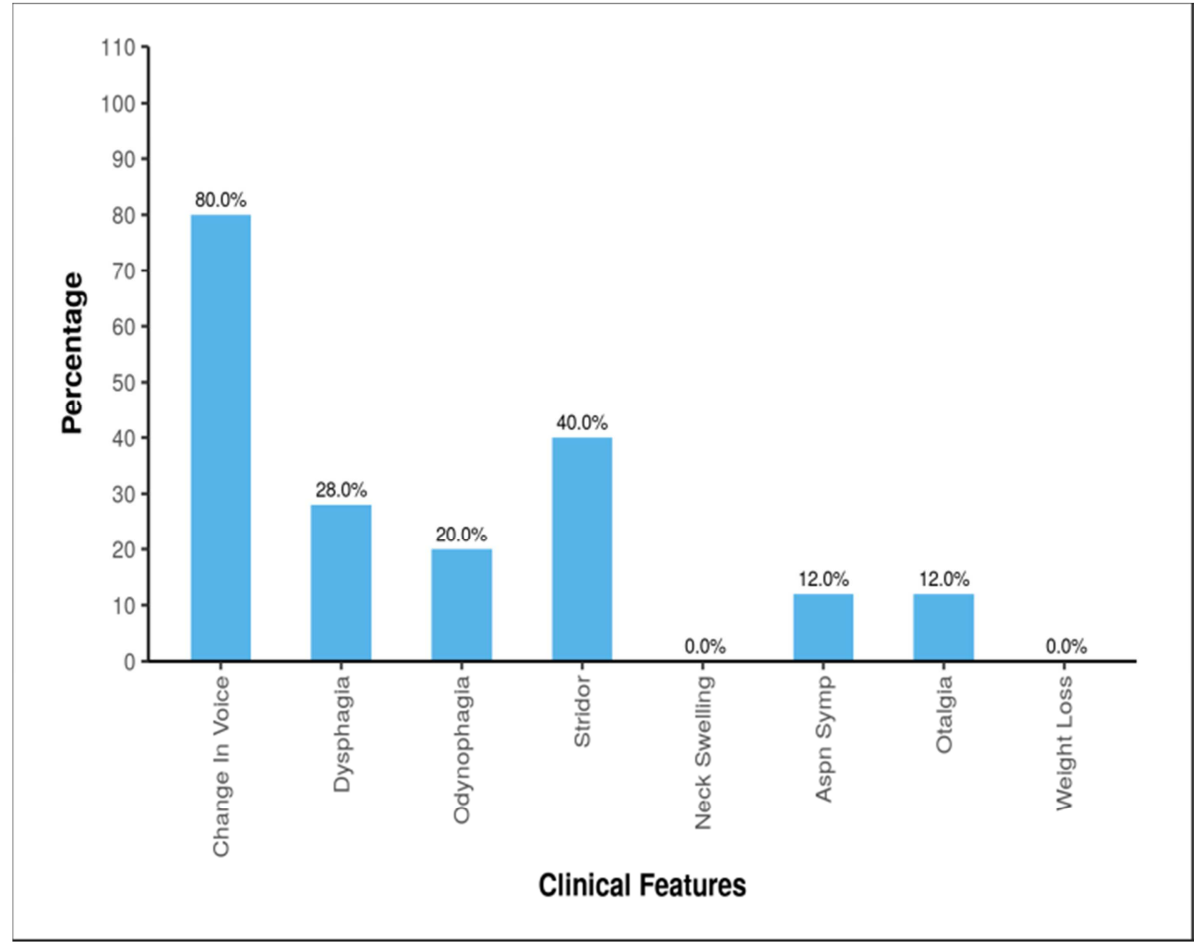

Figure 1. Bar diagram showing clinical features.

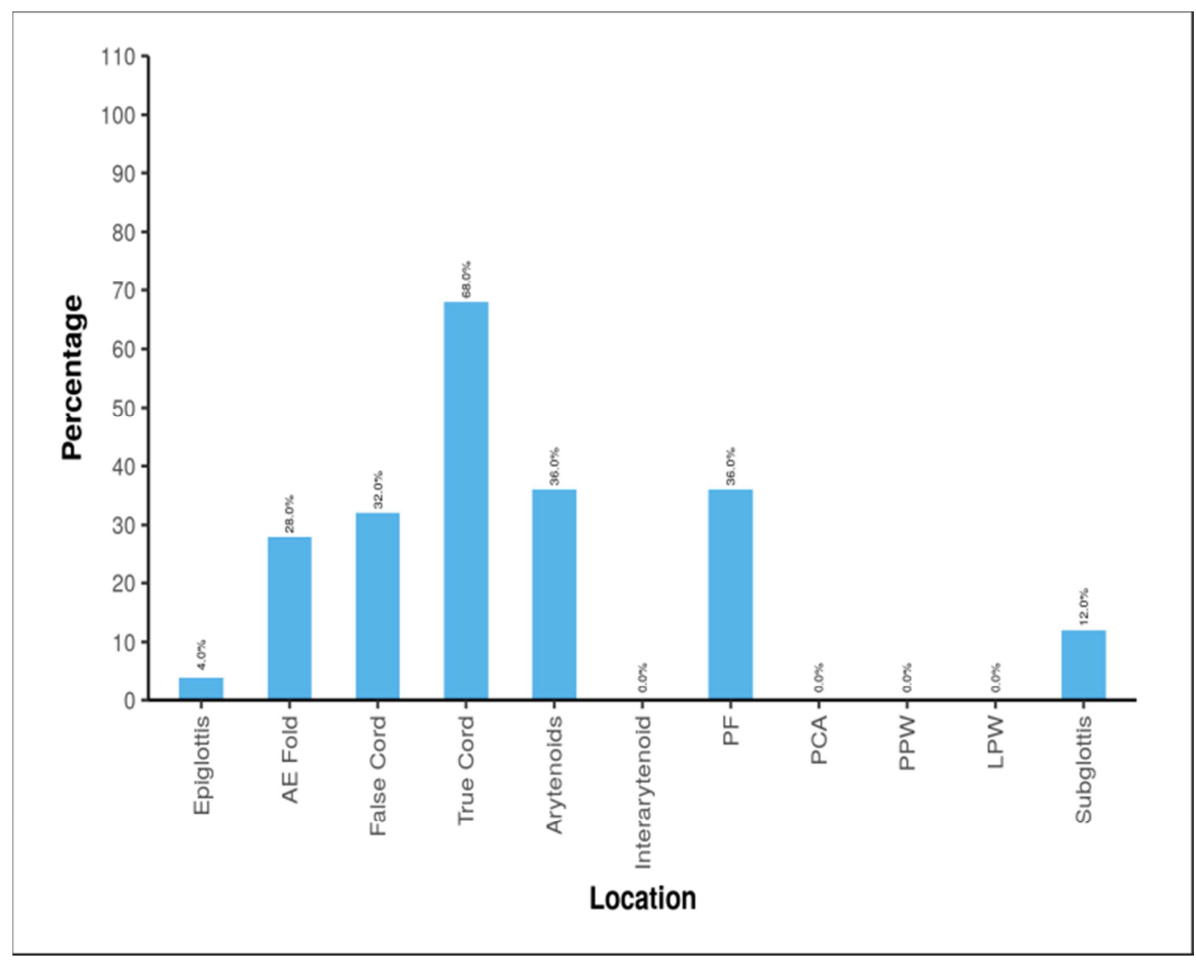

Figure 2. Bar diagram shows involvement of various subsites by the tumor. 
Table 3. Shows association of various risk factors with complications.

\begin{tabular}{|c|c|c|c|}
\hline Parameters & Complications present & Complications absent & p value \\
\hline Age (years) & $60.00 \pm 8.57$ & $57.41 \pm 9.14$ & 0.619 \\
\hline Age & & & 1.000 \\
\hline$<60$ years & $5(33.3 \%)$ & $10(66.7 \%)$ & 1.000 \\
\hline$>60$ years & $3(30.0 \%)$ & $7(70 \%)$ & \\
\hline \multicolumn{4}{|l|}{ Gender } \\
\hline Male & $7(29.2 \%)$ & $17(70.8 \%)$ & \multirow{2}{*}{0.320} \\
\hline Female & $1(100 \%)$ & $0(0.0 \%)$ & \\
\hline Smoking & $6(37.5 \%)$ & $10(62.5 \%)$ & 0.661 \\
\hline Smokeless tobacco & $3(30.0 \%)$ & $7(70.0 \%)$ & 1.000 \\
\hline alcohol & $5(38.5 \%)$ & $8(61.5 \%)$ & 0.673 \\
\hline Both & $5(38.5 \%)$ & $8(61.5 \%)$ & 0.673 \\
\hline Diabetes & $2(66.7 \%)$ & $1(33.3 \%)$ & 0.231 \\
\hline COPD & $1(50.0 \%)$ & $1(50.0 \%)$ & 1.000 \\
\hline Emergency tracheostomy & $5(50.0 \%)$ & $5(50.0 \%)$ & 0.194 \\
\hline \multicolumn{4}{|l|}{ Diagnosis } \\
\hline Ca Supraglottis & $0(0.0 \%)$ & $3(100.0 \%)$ & \multirow{3}{*}{0.473} \\
\hline Ca Glottis & $5(31.2 \%)$ & $11(68.8 \%)$ & \\
\hline Ca hypopharynx & $3(50.0 \%)$ & $3(50.0 \%)$ & \\
\hline Ca Larynx & $5(26.3 \%)$ & $14(73.7 \%)$ & \multirow{3}{*}{0.344} \\
\hline Ca Hypopharynx & $3(50.0 \%)$ & $3(50.0 \%)$ & \\
\hline \multicolumn{3}{|l|}{ cT Stage } & \\
\hline $\mathrm{T} 2$ & $0(0.0 \%)$ & $1(100.0 \%)$ & \multirow{3}{*}{0.782} \\
\hline $\mathrm{T} 3$ & $3(27.3 \%)$ & $8(72.7 \%)$ & \\
\hline $\mathrm{T} 4 \mathrm{a}$ & $5(38.5 \%)$ & $8(61.5 \%)$ & \\
\hline \multicolumn{4}{|l|}{ cN Stage } \\
\hline No & $7(30.4 \%)$ & $16(69.6 \%)$ & \multirow{2}{*}{1.000} \\
\hline N1 & $1(50.0 \%)$ & $1(50.0 \%)$ & \\
\hline \multicolumn{4}{|l|}{ Tumor Stage } \\
\hline III & $3(25.0 \%)$ & $9(75.0 \%)$ & \multirow{2}{*}{0.673} \\
\hline IVA & $5(38.5 \%)$ & $8(61.5 \%)$ & \\
\hline \multicolumn{4}{|l|}{ Neck Dissection } \\
\hline SND & $8(34.8 \%)$ & $15(65.2 \%)$ & \multirow{2}{*}{1.000} \\
\hline MRND & $0(0.0 \%)$ & $2(100.0 \%)$ & \\
\hline \multicolumn{4}{|l|}{ Reconstruction } \\
\hline Primary Closure & $8(34.8 \%)$ & $15(65.2 \%)$ & \multirow{2}{*}{1.000} \\
\hline PMMC & $0(0.0 \%)$ & $2(100.0 \%)$ & \\
\hline Hospital Stay (Days) ${ }^{* * *}$ & $31.88 \pm 8.89$ & $24.24 \pm 3.25$ & 0.011 \\
\hline \multicolumn{4}{|l|}{ pT Stage } \\
\hline pT2 & $1(50.0 \%)$ & $1(50.0 \%)$ & \multirow{3}{*}{0.449} \\
\hline pT3 & $2(20.0 \%)$ & $8(80.0 \%)$ & \\
\hline pT4a & $5(38.5 \%)$ & $8(61.5 \%)$ & \\
\hline \multicolumn{4}{|l|}{ pN Stage } \\
\hline No & $6(33.3 \%)$ & $12(66.7 \%)$ & \multirow{3}{*}{1.000} \\
\hline N1 & $1(25.0 \%)$ & $3(75.0 \%)$ & \\
\hline $\mathrm{N} 3 \mathrm{~b}$ & $1(33.3 \%)$ & $2(66.7 \%)$ & \\
\hline \multicolumn{4}{|l|}{ Postoperative CTRT } \\
\hline Given & $6(42.9 \%)$ & $8(57.1 \%)$ & \multirow{2}{*}{0.234} \\
\hline Not Given & $2(18.2 \%)$ & $9(81.8 \%)$ & \\
\hline
\end{tabular}

\section{Discussion}

Malignancy larynx and hypopharynx are the most common head and neck malignancies presenting to ENT OPD in our institute. Its incidence is on a rise in our population, owing to the increase in the habits of smoking and alcohol which are well established risk factors for it. Smoking is more related to glottic carcinoma whereas alcohol has more effect in causing supraglottic cancer and hypopharyngeal cancers $[4,5]$.

Among 25 patients who underwent TL/TLP, there was male predominance with a male to female ratio of $24: 1$. This is slightly higher as compared to previous studies which states that the disease shows a male predominance with ratio ranging from 5:1 to 20:1 [6]. Many studies reveal that male sex can even be a poor prognostic factor in fact [7]. Mean age of diagnosis among our population was $58.24 \pm 8.87$. This is similar to study by Larbcharoensub et al where mean age of 
diagnosis was $62.08 \pm 9.67$ years [2].

Table 4. Shows comparison of our study with different studies.

\begin{tabular}{llllll}
\hline Complication & Present study & Reddy et al [14] & Sakai et al [12] & Atikuzzaman et al [15] & Maharjan et al [13] \\
\hline PCF & $8 \%$ & $23 \%$ & $26.8 \%$ & $20 \%$ & $30 \%$ \\
Hematoma & $0 \%$ & $6.6 \%$ & $2.8 \%$ & $6.6 \%$ & 10 \\
Free flap necrosis & $4 \%$ & $0 \%$ & $0 \%$ & $6.6 \%$ & 15 \\
Chyle leak & $4 \%$ & $0 \%$ & $2.8 \%$ & $0 \%$ & 10 \\
Carotid rupture & $0 \%$ & $0 \%$ & $1.4 \%$ & $0 \%$ & $0 \%$ \\
Wound infection & $8 \%$ & $23 \%$ & $2.8 \%$ & $0 \%$ & $20 \%$ \\
Wound seroma & $4 \%$ & $0 \%$ & $0 \%$ & $6.6 \%$ & $0 \%$ \\
Stomal stenosis & $8 \%$ & $6.6 \%$ & - & $6.6 \%$ & - \\
Stomal recurrence & $4 \%$ & $3.3 \%$ & - & $6.6 \%$ & - \\
Pharyngeal stenosis & $0 \%$ & $6.6 \%$ & - & & - \\
\hline
\end{tabular}

Since ours is a government hospital majority of our population belong to low socioeconomic status (class 4 and 5 of Kuppuswami's classification) and are either manual labourers or farmers. So occupational exposures to industrial toxins as a risk factor could not be studied here as demonstrated in other studies [8].

Most common presenting complaint was change in voice followed by stridor and dysphagia. This may be attributed to the fact that most common subsite involved was glottis. In a study by Larbcharoensub et al where he studied a total of 212 cases of laryngeal and hypopharyngeal malignancies, most common presentation was hoarseness with $73.6 \%$ patients presented with the same. Most common anatomical site involved by the tumor in our study was true cords followed by arytenoids and pyriform fossa. This is similar to previous studies [2].

Staging was done using AJCC TNM 8 edition staging system [9]. There was good correlation between clinicoradiological $\mathrm{T}$ stage and pathological $\mathrm{T}$ stage except in one case where down staging of the tumor has occurred on pathological reporting. But in terms of clinicoradiological $\mathrm{N}$ staging there were upgrading of $\mathrm{N}$ stage on pathological reporting in case of 5 cases. Postoperative radiotherapy was given for 14 cases, of which three cases received additional chemotherapy, out of which two were because of extranodal invasion and one due to perineural invasion. All surgical margins were negative in the resected specimen. Well differentiated SCC was more common than moderately and poorly differentiated.

Postoperative voice rehabilitation was done with primary TEP for 9 cases (36\%). This is similar to the study by Goepfert et al where primary TEP rate was 33\% [10]. Rest 16 cases esophageal speech was taught for voice rehabilitation, but only 6 successfully acquired it. Few people only acquire successful communication with esophageal speech [11].

Mean duration of hospital stay was $26.68 \pm 6.58$ days. This is similar to previous study where mean duration of hospital stay was 26.7 days [2].

All our patients had postoperative feeding via nasogastric tube and it was removed on postoperative day 10 after trial of oral feeding. Two cases which had PCF, nasogastric tube was retained further for 15-20 days till fistula closed.

Overall wound complication in our study was $32 \%$ similar to the study by Goepfert et al [10] where complication rate was $33.9 \%$. Among the primary surgery group in the study by Sakai et al [12] it was $35.2 \%$ whereas it was $37 \%$ in the study by Maharjan et al [13]. Most common complications in our study were wound infection and PCF similar to previous studies $[13,14]$. There were 2 pharyngeal leak cases both of which were managed conservatively. There were two cases of wound infection and dehiscence one of which led to flap necrosis. Pus culture and sensitivity was sent from wound infection site and treated accordingly with sensitive antibiotics. Flap necrosis was managed by skin grafting from thigh. One wound seroma $(4 \%)$ was there which was secondary to premature drain removal. It was managed conservatively with pressure dressing. One case of chyle leak was there (4\%). One case of stomal stenosis was there detected on $3^{\text {rd }}$ month follow-up, and was treated with dilatation. Another case of stomal stenosis along with stomal recurrence was noted in the 6 month follow-up and sent for palliative chemotherapy. There was not a single case of neopharynx stenosis during 6 months follow-up. We didn't have any case of wound hematoma, carotid blowout or hypoglossal palsy.

In our study none of the factors like age, gender, presence of addictions, preoperative tracheostomy, diagnosis, site involved, tumor stage, nodal status, presence of neck dissection, postoperative chemoradiotherapy turned out to be significant risk factors for complications. Previous studies have shown preoperative tracheostomy has got more risk for stomal recurrence [16]. In our study one case which developed stomal recurrence had preoperative emergency tracheostomy, but we could not establish a statistical significance for the same. In the study by Sakai et al [12] diabetes mellitus was established as a significant risk factor for complication rate, but in our study we could not establish the same. PCFs are generally reported to be higher in hypopharyngeal malignancies, as in the study by $\mathrm{B}$ $\mathrm{T}$ Varghese et al [3] but in our study even though both PCF were seen in hypopharyngeal malignancy, no statistical significance could be derived.

Mean length of hospital stay among TL/TLP cases with wound complications was 31.88 where as it was 24.24 days in case of cases without complications. There is significant difference between mean hospital stay of cases with complications and without complications. Patricia Garcia et al in their study states that postoperative fistula is a major problem and is the main cause for prolonged hospital stay and postoperative morbidity [17]. In our study also there was significant difference 
between hospital stay among cases with PCF and without PCF $(p=0.044)$. So once complications set in, it increases hospital stay and thus adds to the expenditure, and hence is more traumatic to the patients. Hence complications are not only nightmare to the surgeons but also to the patients.

\section{Conclusion}

TL/TLP is the treatment of choice for locally advanced laryngeal and hypopharyngeal malignancy. Malignancy larynx and hypopharynx are predominant in males with smoking and alcohol being important risk factors. Glottic malignancy is more common than supraglottic and pyriform fossa malignancy, and change in voice is the most common presentation of the same. Most common histological variant is well differentiated squamous cell carcinoma. Overall complication rate is $32 \%$ in our population following TL/TLP. Through our study we found that incidence of complication increases the hospital stay and thus leads to financial burden on the patients. With proper case selection, and proper postoperative care and regular follow-up, complications can be avoided in case of TL/TLP.

\section{Limitations and Future Directions}

As our study was conducted for a follow-up period of 6 months we could not encounter much of the late complications like neopharynx stenosis and local recurrence. As our study period was limited, the sample size was small and hence we could not assess the statistical significance of risk factors associated with individual complications encountered. So it would have been better if we would have extended the period of study to 2 years with a follow-up period of 1 year. In future, if studies are undertaken on the same, then it will be better if period of study and sample size are more, so that risk factors associated with individual complications can be derived.

\section{References}

[1] Varghese BT, Babu S, Desai KP, Bava AS, George P, Iype EM, Rajan B, Sebastian P. Prospective study of outcomes of surgically treated larynx and hypopharyngeal cancers. Indian journal of cancer. 2014 Apr 1; 51 (2): 104.

[2] Larbcharoensub N, Wattanatranon D, Leopairut J, Suntisuktana S, Roongpupaht B, Chintrakarn C, Tungkeeratichai J, Praneetvatakul P, Bhongmakapat T, Cheewaruangroj W, Prakunhungsit S. Clinicopathologic Findings and Treatment Outcome of Laryngectomized Patients with Laryngeal Cancer and Hypopharyngeal Cancer: An Experience in Thailand. Asian Pacific Journal of Cancer Prevention: APJCP. 2017; 18 (8): 2035.

[3] Varghese BT, Sebastian P, Mathew A. Treatment outcome in patients undergoing surgery for carcinoma larynx and hypopharynx-a follow-up study. Acta oto-laryngologica. 2009 Jan 1; 129 (12): 1480-5.

[4] Watkinson J, Gilbert R. Stell \& Maran's textbook of head and neck surgery and oncology. CRC Press; 2011 Dec 30.

[5] Ramakodi MP, Kulathinal RJ, Chung Y, Serebriiskii I, Liu JC, Ragin CC. Ancestral-derived effects on the mutational landscape of laryngeal cancer. Genomics. 2016 Mar 1; 107 (2-3): 76-82.

[6] Alagic-Smailbegovic J, Kapidzic A, Sutalo K, Resic M, Hadzic E. Incidence of malignant tumors of larynx and their treatment. Bosnian journal of basic medical sciences. 2004 Nov; 4 (4): 25.

[7] Villanueva-Reyes A, Strand E, Nazario CM, Irizarry-Ramirez M. Cancer of the larynx in Puerto Rico. Puerto Rico health sciences journal. 2008 Sep; 27 (3): 196.

[8] Grignoux J, Durand-Moreau Q, Vongmany N, Brunel S, Dewitte JD. Work-related laryngeal cancer: Trends in France from 2001 to 2016. European annals of otorhinolaryngology, head and neck diseases. 2019 Feb 1; 136 (1): 7-12.

[9] Amin MB, Edge SB, editors. AJCC Cancer staging manual. springer; 2017.

[10] Goepfert RP, Hutcheson KA, Lewin JS, Desai NG, Zafereo ME Hessel AC, Lewis CM, Weber RS, Gross ND. Complications, hospital length of stay, and readmission after total laryngectomy. Cancer. 2017 May 15; 123 (10): 1760-7.

[11] Staffieri A, Mostafea BE, Varghese BT, Kitcher ED, Jalisi M, Fagan JJ, Staffieri C, Marioni G. Cost of tracheoesophageal prostheses in developing countries. Facing the problem from an internal perspective.

[12] Sakai A, Okami K, Sugimoto R, Ebisumoto K, Yamamoto H, Furuya H, Iida M. Multivariate analysis of wound complications after surgery for laryngeal and hypopharyngeal cancers. ORL. 2011; 73 (2): 100-4.

[13] Maharjan R, Adhikari P, Khalilullah S, Sinha BK, Baskota DK. Early complications of total laryngectomy: a retrospective study. Nepalese Journal of ENT Head and Neck Surgery. 2010; $1(2): 17-8$.

[14] Reddy SL, Reddy SD, Prasad AV. A Prospective Study of Total Laryngectomy and associated Complications. Int J Phonosurg Laryngol. 2012; 2 (1): 20-2.

[15] Atikuzzaman K, Ahmed KU, Hassan M. Postoperative complications and its management after total laryngectomy. Bangladesh Journal of Otorhinolaryngology. 2013; 19 (2): 82-6.

[16] Liang J, Zhu X, Zeng W, Yu T, Fang F, Zhao Y. Which risk factors are associated with stomal recurrence after total laryngectomy for laryngeal cancer? A meta-analysis of the last 30 years. Brazilian journal of otorhinolaryngology. 2020 Apr 11 .

[17] Herrero PG, Fernández-Vañes L, Álvarez FL, Marcos CÁ, Llorente JL, Rodrigo JP. Results of total laryngectomy as treatment for locally advanced hypopharyngeal cancer. Acta Otorrinolaringologica (English Edition). 2017 Nov 1; 68 (6): 328-35. 